\title{
A Model of Virtuous Leadership in Africa: Case Study of a Nigerian Firm
}

\author{
Adeyinka Adewale ${ }^{1}$
}

Received: 10 September 2018 / Accepted: 30 October 2019 / Published online: 11 November 2019

(c) The Author(s) 2019

\begin{abstract}
The nature and extent of Africa's leadership challenge has been explored from multi-theoretical perspectives finding that amongst other issues, it is ethical in nature. This study therefore aimed to investigate and present a model of virtuous leadership within an indigenous African firm's context drawing from the African virtue ethics of Afro-communitarianism. Using a qualitative case study design, it explored a model of virtuous leadership within a leading Nigerian pharmaceutical brand. Data was collected from multiple primary sources including semi-structured interviews and informal conversations as well as secondary sources. This study found a virtuous leadership model underpinned by four African primary virtues-Truthfulness, Courage, Humility and Humanity within a context of communitarianism. It also found that the nature and practice of these four virtues by the leaders within the context positively shaped employees' moral characters through visible modelling but not without its flaws. It concluded that virtuous leadership models are essential within the African leadership context to rise above existing status quo to build communities of practices that are not business as usual but seeking the ultimate end of facilitating the flourishing of immediate and wider communities alike.
\end{abstract}

Keywords Virtuous leadership · Virtue ethics · Leadership in Africa

\section{Introduction}

A thriving body of work studying leadership in Africa has seen increased attention providing significant multi-theoretical insights on the history, challenges, styles and overall magnitude of Africa's leadership issues (Malunga 2006; Nkomo 2011; Ngambi 2011; Masango 2003; Williams 2003; Mbigi 2007; Spangenberg and Theron 2002). A more apparent issue is that Africa's leadership challenge tends to have a moral undertone but, like Everett et al. (2006) observed, a review of typical recommendations in ethics studies that have been published on Africa showed the tendency for scholars to be obscured by a focus on 'actions', rather than 'actors'. Where there has been a focus on actors, there seems to be an assumption to instil a greater sense of morality into such actors (i.e. what constitutes right and wrong). This perspective implicitly assumes that morality can be "added on" to a person yet; evidence of increasingly poor leadership on the continent seems to suggest a need to focus on

Adeyinka Adewale

adeyinka.adewale@henley.ac.uk

1 Henley Business School, University of Reading, Whiteknights Campus, Reading RG6 6UD, UK how individuals and firms make their moral choices given contextual constraints. Advancing this perspective involves looking into how moral leaders should act in a typical African context of communitarianism. This paper therefore aims to contribute to the discourse on leadership in Africa by investigating a model of virtuous leadership as practiced in a Nigerian firm, drawing from the African ethic of Afrocommunitarianism. More specifically, this paper will explore what virtuous leadership should look like within a typical African context of communitarianism.

This study's focus took its roots from a broader, prior study conducted by the author, investigating the interactions between organisational contexts, especially corporate bureaucracies and individuals' moral identities in the Nigerian pharmaceutical sector. The corporate contexts of three pairs of American, Indian and Nigerian firms were investigated respectively in relation to the macro environment in which they operated and the subsequent impact they had on employees' moral identities. Findings identified a unique leadership model in one of the indigenous Nigerian firms that had a strong positive impact on employees' moral identities. This leadership model differed significantly from the leadership models present in all other case studies and demonstrated significant positive deviance (Spreitzer and 
Sonenshein 2003) worth investigating further. This firm was discovered to have built an unusually positive and ethical reputation for over two decades within a national and business context typically classified as corrupt and hostile (Transparency International 2018; World Bank 2019). Consequently, the author became interested in knowing how this indigenous African organisation seems to have an ethical reputation despite doing business in an 'unethical' context, hence the focus of this paper.

Insights on the Nigerian firm's context from the prior study revealed a culture of excellence similar to the concept of 'arête' in virtue ethics (Neubert 2011; Thun and Kelloway 2011; Juurikkala 2012; Crossan et al. 2013) and a strong moral influence of the leaders' characters on employees' moral dispositions within the firm. These initial impressions informed the notion of a 'virtuous leadership model' presented in this study and influenced the choice of virtue ethics in investigating this leadership model. Furthermore, the depiction of a strong sense of community and family in both the firm and wider context further informed the decision to deploy a community level African virtue ethics theory in making sense of the firm as a community and its leaders' actions.

Virtuous leadership suggests that leadership is entrenched in certain virtues (Wang and Hackett 2016) thereby creating "a system of ethical thought which considers the development and nurture of moral character as the best way to affect moral behaviour and moral society" (Palanski and Yammarino 2009, p. 176). As such, this study explores the African primary virtues that make up this model of virtuous leadership through the lens of Afro-communitarianism, an African virtue ethics based on Ubuntu (Metz and Gaie 2010). In doing so, it is intended that this research acknowledges that the concept of virtuousness varies somewhat by culture (Hursthouse 2007; Melé 2005) and that the approach adopted in this study will advance the African management literature by investigating and presenting a model of leadership that can thrive within the complex African context. Whilst this study intends to present a model of virtuous leadership in an African context, it is not necessarily implying that the primary virtues embedded in this model are necessarily exclusive to Africa but that in the context of this research, they are pertinent to effective leadership given the nature and scope of issues presented in the specific context studied. Also naming the virtues espoused within this study's context as 'African primary virtues' is not an attempt to generalise them as being the same in every African country, rather it is to acknowledge they are some of the many virtues embodied by the Afro-communitarian ethics and may manifest differently in other African countries contexts.

In the spirit of this special issue, which aims to provide more coverage for African theories, models and firms, it is believed that the concept of virtuous leadership presented in this paper could benefit the leadership literature in Africa in a number of ways. Firstly, it offers a model of leadership that is not necessarily a superimposition of western ideologies on Africa as Malunga (2006) suggests but is derived inductively from an indigenous African context. As such, it can be argued that the African "primary" virtues to be presented function analogously as the "cardinal virtues" worked in the ethics of Aristotle (Papouli 2018). Secondly, it presents a virtuous leadership model that has been in operation for over two decades whilst highlighting the specific virtues that make it practicable in the African context. Thirdly, exploring virtuous leadership in different African contexts can help uncover and advance our understanding of African philosophies especially their strengths and weaknesses. These can ultimately contribute towards developing useful theories and models of leadership for Africa and the broader management and leadership literature.

The remainder of this paper is structured as follows: the African virtue ethics of Afro-communitarianism and Ubuntu are discussed from existing literature highlighting their functioning at the societal and firm levels respectively. Then it presents the case study of a virtuous model of leadership in the case study firm with a detailed description of the macro, industry and firm context in which it thrives. From these, key findings on the African primary virtues espoused in the model of virtuous leadership studied are presented, as well as the kind of effect they have on the moral climate of the organisation and on employees. Thereafter it discusses concluding thoughts and implications for the African leadership and Afro-communitarianism ethic literatures.

\section{The African Ethics of Afro-communitarianism and Ubuntu}

Community is widely accepted as a characteristic feature of African and indeed sub-Saharan existence (Metz 2013). Salient value is often placed on communal functioning within this region in a way that it tends not be elsewhere. In other words, community is not taken for its instrumental value alone such as improving people's wellbeing or vitality but as a basic moral value that is good in itself and for its own sake (Shutte 2001; Nkondo 2007; Metz 2012). In the African tradition, the meaning of community transcends the mere existence of a group or society, it is used to refer to an ideal governing how members of a group relate and interact. Therefore, embedded in this notion of the community is the sense of both the identity it offers the individual as well as the demands for acting in solidarity towards others or what can be called the common good (Metz 2013).

Masolo (2010) submitted that charity and other virtues of altruism such as politeness and benevolence to others are perhaps the most celebrated aspects of African 
communitarian practices and ideals. In West Africa, moral virtues embraced in communities include generosity, kindness, compassion, benevolence, respect and concern for others (Gyekye 1992). In South Africa, communal moral virtues such as deeds of kindness, compassion, caring, sharing, solidarity and sacrifice are prevalent (Mnyaka and Motlhabi 2005). Peter Paris (1995) summarised the view of essential virtues in African communities as beneficence which he remarked exemplifies the goal of community (p. 136). Thus, African moral philosophers tend to highlight other-regarding actions and virtues commonly associated with altruism as the central virtue characterising Afro-communitarianism.

In the functioning of African communities, African ethicists often conceive community in terms of the way that family members relate or should relate to one another. The extended family is probably the most common, and also the most essential expression of the African idea of community (Shutte 2001). The importance of this idea for ethics is that the family is something that is valued for its own sake (Metz 2013). Consequently in defining who a moral person is or what constitutes good character, communitarianism thinks of it in relational terms such that as Metz (2013) submitted, the rationale for determining whether an action is wrong is on the basis of failure to relate. Thus, in the African tradition, morality is summed up in the maxim of 'a person is a person thorough other persons' or 'I am because we are', otherwise called Ubuntu. While the community identifies, encourages, and enforces moral behaviour, the hope of most communities is that individuals will at some point internalise the appropriate moral principles and seek to practice these virtues for their own sake. By doing this, individuals, in a classic Aristotelian sense, become virtuous people (Limbs and Fort 2000). This further forms the basis of our understanding of what the common good of the society is, in this case, communal flourishing.

Thus, the relational nature of ethics in the context and practice of communitarianism highlights the role of familial relationships in shaping moral norms. However, Keeley (1988) warns that this notion of morality highlights inherent weaknesses, primarily issues of relativism and also in that communities can easily become dangerous places through the pronouncement of their leaders. Also, other factors that mediate the functioning of communities and how ethics is shaped including ethnicity, language and religion could affect the way members who are not in power are treated.

\section{Communitarianism in African Firms}

So far, this paper has considered communitarianism at the wider society level. What might communitarianism then look like at the firm level? Limbs and Fort (2000) suggested the theory of "business-as-community" in describing the functioning of communitarianism at the firm level. In their position, it is reasonable to accept businesses or firms as communities in as much as in the broader virtue ethics literature, firms are considered as intermediate bodies, situated between individuals and families, on the one hand, and the political community, on the other (Sison and Fontrodona 2012). Therefore, like any other community, firms define the end for which they exist and also develop the norms considered as meaningful and acceptable within their specific context. In addition, they socialise individuals into knowing the virtues to embrace and the vices to avoid towards achieving the firm's end as well as its common good. Interestingly in the context of African firms, it can be argued that the divide between the concept of community in the wider society and at work may be non-existent because of the family-owned nature of most private businesses (Limbs and Fort 2000). Therefore, just like in the wider society, the common good of the firm is rooted in the concept of 'collaborative work' everyone working together towards achieving the end of the organisation. It therefore follows that social accountability is the 'enforcement' mechanism in firms' communal contexts.

This conceptualisation of communitarianism in both African societies and firms highlights the role of leaders as key proponents of moral virtues in an ideal context. In the Aristotelian virtue ethics tradition, the polis or state through its leaders are meant to use laws and practical wisdom in encouraging the practice of virtues with a view to making members of the polis virtuous persons. Likewise in the African ethic of communitarianism, visible leaders such as family heads and elders of the community play a very similar role in ensuring communal virtues are embraced and enforced. They are the proponents and the face of community virtues and tend to wield a lot of influence in determining the outcome of situations within the community. But in a compromised context, such as we have in many African countries, that is a context where the leaders leverage their influence for personal gains instead of for the common good, what becomes of the 'common good'? And more importantly for firms functioning in such compromised contexts, how should their leadership respond? The easiest and perhaps most popular option is to conform to prevailing societal standards, an option that offers the least resistance and tends to promise handsome rewards. Yet, another option is for firms' leaders to demonstrate, albeit very rarely positive deviance, which is the moral thing to do yet is fraught with daunting resistance as well as meagre rewards in most instances.

The nature of this dilemma is further underscored by the fact that virtue ethicists often suggest that firms play 'complementary' roles towards achieving the wider societal common good (Beadle and Moore 2006, 2011; Moore 2008; Beadle and Knight 2012). Therefore, in as much as firms are not seen as being responsible for the common good of the society, they are responsible to it and in doing this, their 
activities must be compatible with the common good of the society (Agandona 2009). Furthermore, virtue theory submits that the essence of leadership is to exercise 'practical wisdom' in order to nurture and encourage virtue in other members of the community. Therefore, whilst it follows that the functioning of the society-firm bilateral relationship in a compromised communitarian context becomes rather complex, it also begs the question-what model of firm leadership is required to successfully navigate such compromised contexts? Assuming there is a leadership model that defies the odds to demonstrate a significantly positive deviance in such a context, what might this model of leadership look like? A potentially useful leadership model in a compromised context of communitarianism is subsequently explored.

\section{Methodology}

\section{Research Context}

The choice of a context for this research in accordance with its objectives was predicated on two factors: a well-known corrupt context and a fast-paced, economic hub for firms in different industries, both of which Lagos, Nigeria offered. Nigeria is Africa's biggest economy typified as corrupt and fast-paced with weak institutions (Transparency International 2018). The choice of the pharmaceutical industry in particular was also guided by the ethically sensitive nature of the industry as well as a long history of ethical issues including drug adulteration, illegal drug trials, bribery, and corruption amongst other critical issues (NAFDAC 2015) that lend the industry to the discourse of ethics within this context. Reports on the Nigerian pharmaceutical landscape from the World Bank (2014) and United Nations Industrial Development Organisation (UNIDO 2013) and Transparency International (2018) reveal five crucial contextual features that typify the Nigerian pharmaceutical industry as follows: Illegal processes, corrupt government officials, greed, economic uncertainty and stiff market competition. Furthermore, stiff market competition within the industry (IMS Health 2012) caused by the fast-growing economy has also exposed firms to newer waves of ethical problems centred around profit maximisation at the expense of saving lives, thereby creating a context charged with high moral tensions (Erhun et al. 2001; Garuba et al. 2009).

More specifically within this industry context, regardless of an employee's professional background, the bulk of responsibilities lie in the sales of company products to different types of customers. Hence, in a saturated market with large foreign multinational players boasting of 'superior' products compared to indigenous firms, employees of local companies have to rely on their selling techniques and abilities or 'street smartness' to compete successfully in order to meet their sales targets. In doing this, many cross moral boundaries, resorting to bribery, undercutting colleagues to sell more products and a host of other unethical practices. All these validate the choice of this macro and industry context as a viable ground for an ethics research looking to present a thriving model of virtuous leadership within such a context typical of most African countries.

\section{Research Design}

Coe and Beadle (2008) identified a broad range of methods appropriate for doing empirical studies in virtue ethics and identified the need for rich descriptions through narratives (Beadle and Moore 2011). Therefore, the case study design, which Baxter and Jack (2008) opined "affords researchers opportunities to explore or describe a phenomenon in context using a variety of data sources" (p. 544) is perhaps the most appropriate approach to exploring virtue in business organisations. In line with the broader objective of investigating and presenting a model of virtuous leadership in an indigenous African organisation, the case study approach was apt. In selecting the specific case for this study, the author wanted to investigate only large fully owned indigenous Nigerian pharmaceutical companies, big enough to generate attention if caught up in any scandal. To get this, the author opted only for companies that are quoted on the Nigerian Stock Exchange. In addition, the author was interested in firms with a proven record of both leadership and industry accomplishment with no reported scandal in the firm's history. To get this, the author looked out for the number and consistency of awards such firms win at the end of each year which are typically based on leadership, excellence and overall firm performance. It was believed that firms that met these criteria would make for an excellent sample population for a study that aims at understanding a model of virtuous leadership being presented in this study. Our search returned only one company given the pseudonym 'Pharma Nigeria Plc' (hereafter referred to as PNP), which became our focus for this study.

\section{Case Study Firm}

Pharma Nigeria Plc (PNP) is a 23-year-old wholly owned Nigerian firm with an annual revenue of about $\$ 40$ million and employing about 314 people at its Headquarters and over a thousand employees in total. In the last 5 years, PNP has consistently received different categories of leadership and industry standards awards such as excellence in leadership awards, pharmaceutical company of the year award, business leadership awards and others making it one of the most decorated Nigerian pharmaceutical companies. Narratives by past and present employees of the firm suggests 
a culture of excellence and integrity has been deliberately built and instilled in employees through the visible modelling of such virtues by the senior management of the firm. Employees within this context typically show a lot of admiration and respect for the leadership of the firm, particularly the Managing Director/Chief Executive Officer (MD/CEO), known for his charisma and rags to riches story.

The MD/CEO is described as humble, friendly and approachable such that any of the firm's employees can ask for an audience with him at any time. Like the MD/CEO, the senior management team also reflect the core character traits of their leader making them earn the respect of their employees. Therefore, the atmosphere within the organisation is very calm and cordial with top management often freely interacting with all levels of employees. An employee submitted that their managers are the face of the values of the organisation and that as employees; they typically embrace the values they see in the leaders they respect. Interestingly, standard operating procedures do not govern many processes within this firm, however; employees have a common understanding of the values that bind them as an organisation.

In addition, the board of trustees of PNP include some notable moral exemplars figures in the Nigerian medical field. Besides the cordiality and warm relationships, there is a Christian fellowship for employees within the organisation. Some of the staff point to the fellowship as a "strong moral reinforcement' for them and one that is held in very high esteem within the firm. The kind of context this has created is described as 'free', 'inspiring' and 'ethically sound' and the company prides itself on having over 100 employees who have served for more than 10 years. In response, employees feel very comfortable working in such a huge establishment and would often use the words 'privileged' 'honoured' with a sense of joy that a Nigerian firm is stepping up with strong values in a poor institutional context. So far, in the history of the company, there has been no publicly reported scandal involving this firm, therefore, making it a good case study on virtuous leadership. The opportunity to study this organisation arose through a direct contact with the Director of Human Resources who graciously gave the author access into the firm and its employees. Both senior and junior employees of the firm freely participated in the interviews conducted by the author. The permission granted also allowed the author to observe the firm's daily operations for two weeks.

\section{Data Collection and Analysis}

This research employed an inductive, qualitative approach in order to generate inferences from the sample. It employed multiple data sources comprising of primary data acquired through semi-structured interviews used in interrogating employees of PNP and multiple secondary sources including company's annual reports, newspaper articles and established online platforms such as 'Glassdoor' where past and present employees voluntarily rate and share experiences of working with their employers. Overall, nine employees of PNP comprising three employees each were selected and formally interviewed across the three different management levels (lower, middle and upper levels). The selection was based on roles having constant interaction with the MD/CEO and the upper echelon of the firm whilst also interfacing with external agents, which expose such employees to the realities of the macro contextual challenges of the Nigerian context. Table 1 below shows a summary of the nine respondents engaged in this study:

In addition to these nine respondents, the author had the privilege of observing and interacting with twenty other members of staff who met the criteria of staff this study required but were not formally interviewed. Instead, research notes taken from personal observations and informal interactions with them at lunch breaks, and informal meetings also formed part of the data considered in this study. The nature of such informal conversations was such that they allowed for open and honest conversations since they were off the record. Also, haven been visiting the firm for many days, and having lunch with staff at the company's cafeteria, I had become like a pseudo staff many employees had come to recognise hence it was easy for conversations to happen. But in further encouraging open and honest conversations with all staff members I interacted with participants during this research process, interviews and informal chats took place in different enclosed and private locations within the premises of the firm. These included places like closed, unshared offices, small meeting rooms and at times in the company's parking lot.

Interview questions and informal chats covered four main topics: 1. Respondents perception of the firm prior to working in the firm and subsequently as an employee; 2. Specific job and contextual challenges and how the

Table 1 Table of respondents

\begin{tabular}{llc}
\hline Respondent & Respondent's role & $\begin{array}{l}\text { Number of } \\
\text { years in PNP }\end{array}$ \\
\hline PNP1 & IT Manager & 2 \\
PNP2 & Operations Officer & 3 \\
PNP3 & Product Manager & 6 \\
PNP4 & HR Officer & 10 \\
PNP5 & Admin Assistant & 4 \\
PNP6 & Internal Auditor & 2 \\
PNP7 & Corporate Services Manager & 5 \\
PNP8 & Personal Secretary & 4 \\
PNP9 & Compliance officer & 6 \\
\hline
\end{tabular}


firm empowers employees in handling them; 3. Perception of the firm's leaders and the leadership culture; 4 . the nature of employees' personal development since joining the firm. These broad question themes ensured the questions asked were not leading questions thereby controlling for social desirability bias. In addition, the author asked 'dummy' questions around the most important things to the participants at work and outside of work amongst other questions that gave clear insights into the moral values of the participants held as central to their self-definition. These questions helped the interviewer check for alignment of values. Also, in controlling for bias with the formal interviews, the use of data obtained during informal chats, which tended to be more critical of firm's leadership and culture helped balance out the views on the firm. It must also be noted that the author used informal chats to further test the authenticity of certain views posited during formal interviews in addition to secondary data, all of which ensured a robust and balanced view of happenings in the firm community were captured. The interviews took place over a 2-week access period between February and April 2014 and each formal interview typically lasted $2 \mathrm{~h}$ whilst informal chats averaged 30 to $40 \mathrm{~min}$.

Subsequently, transcribed interview data and research notes were analysed using the six-step thematic analysis by Braun and Clarke (2006). Transcripts totalled 224 pages and formed the corpus of analysis uploaded into the MaxQDA software. The author read each transcript in detail to understand the content and level of detail provided by the participants. By this, the sufficiency of the data collected was ascertained in line with the objectives of this study. Creating codes needs a balance of rigour, logic and creativity in order to build a frugal and operational system of categories (Braun et al. 2014). Based on the suggestion of Strauss and Corbin (1994) a coding process that involved progressive coding techniques was applied using features on the MaxQDA software for open coding, axial coding and selective coding. The coding process was executed along three broad themes as Hackett and Wang (2012) opined in their definition of virtuous leadership. First, this study coded for the features of the firm's communitarian context in which the virtues were practiced as suggested by Wang and Hackett (2016). Second, it coded for the African primary virtues that made up the model of leadership within the firm - that is the key virtues of the leaders based on aggregated data. In doing this, it relied on the features of virtue based on Aristotelian virtue ethics as posited by Murphy (1999), and thirdly, the underlying processes of how the virtues influenced employees. Based on these three broad themes, key findings are presented below:

\section{Findings and Discussion}

\section{Firm's Communitarianism Context and Leadership}

PNP is a firm characterised by its family-like work environment. The structure of this organisation is such that there is a wide span of control, with more than five direct reports to managers depending on the department, thus, giving employees a great degree of independence. Also, this firm showed a preference for a very cordial, informal system such that even though there are clear hierarchies, upper management layer and the lower level roles naturally interact without rigid boundaries based upon formalised roles. The firm is headed by a well-respected Nigerian Chief Executive, representing the interest of an all-Nigerian board of directors, also comprising of highly reputable individuals. The senior management team also comprises only Nigerian nationals. Together, both managers and their subordinates often work very closely together without any perceived 'power distance' amongst the hierarchies of the firm.

As such within this case study, it was found that the $\mathrm{MD} / \mathrm{CEO}$ and his management team were described to exude certain levels of sanctity, which makes employees regard them as heroes and role models. In other words, the $\mathrm{MD} / \mathrm{CEO}$ and his team through their character and conduct make the moral values they hold in esteem visible, such that they impact how employees perceive the team and the organisation. This notion was a dominant theme throughout the interviews and informal chats with staff across multiple departments and hierarchy as shown below:

When you see men you can look up to and I can tell you I have found several of them in PNP and they are like driving forces for me. The MD has been like a huge inspiration to me... (PNP4)

I first thought PNP was a multinational owned by foreigners ...I never knew it was owned by a Nigerian so it was when I came by that I discovered that and I was so amazed and that the man (MD) is someone that is a visionary leader, I respect him a lot. I never knew anybody here, I just applied and I got the job... (PNP6)

From the quotes above, the positive effects of leadership can be seen in the way that employees describe and revere the leadership of the organisation. For instance, employees seem to be satisfied with their jobs because of the cordial nature of the work environment owing largely to the likeable visionary leadership of the firm as much as employees seemed to see in their leaders individuals worthy of being their role models and mentors. The MD, for instance, is described as a visionary leader, known for his Christian 
beliefs; he is also known to be quite free, approachable and easy to talk to. Further, he is described to have the ability to see potential in his employees and would often help them nurture it. This sentiment was also collaborated by former employees of the firm through secondary sources.

This kind of relationship between managers and their subordinates comes across as an inspirational one that creates an environment of mutual trust based on the mutual respect employees seem to have for their superiors and vice versa. The quotes above also suggest that the leaders within this firm exude virtues that the firm taps into. For instance, the managing director was reported to have very strong religious roots, from which his value system is derived. This was discovered to have informed the norm of daily morning prayers and fellowship within the organisation as explained below:

Predominantly in PNP, we have an ethical standard. The management team always pushes that into us... We do Fellowship (prayers) 8 AM to 9 AM every morning...It is more or less like an official thing... they hold on to religious values and I think religious values are the best standards... (PNP2)

I think they have that spirit of Fellowship, of friendliness here...We have a fellowship centre downstairs... that is the culture here...people are open and there is nobody that is too big, everybody's cordial. The MD can come here now, they can even eat with you, very simple, it's a really nice place (PNP6)

As such, it seems that the person (character and conduct) of the managing director has a huge effect on how employees perceive the organisation and its management team. The religious beliefs of the MD, for instance, encourages the fellowship within the firm where employees freely pray together every day without obligation. This can also be argued to have its effect on employee moral conduct and disposition whilst promoting a sense of shared values in the community. Employees also reported that leaders within the organisation lead by example, often demonstrating their deeply held values in conduct and character by the way they handle their work as a participant explained below:

I'll give them integrity; they really try to do what they say they do. Sometimes in seeking money you can get carried away, you can't cut corners and shortcuts and all that. At least I work closely with the people that are at the helm of affairs in decision-making and sometimes when there are issues the way they pick it up like our name is at stake... (PNP5)

The testimony of the participant above suggests that when leaders show through direct association and continuous modelling the virtues they stand for, they are further respected, admired and followed. Thus, as one of the participants above explained, a prevalent and accepted understanding among employees is that the ethics of the firm is grounded in Christian values hence there is a common knowledge that PNP has high standards of morality as employees also perceive from the observable conduct of their leaders. These, in turn, create an environment of social accountability in which employee conduct and performance can be informally monitored.

The system of social accountability is a self-regulatory control mechanism based on mutual trust in which the employees themselves have a sense of shared responsibly based on commonly held beliefs acquired from their leaders to act only in ways that are in line with the firm's values. Through this shared belief mechanism, violations are easily spotted and dealt with accordingly as one of the managers explained below:

In a system that has been able to thrive itself for more than 20 years based on the fact that people have a high level of integrity, then definitely it will be very difficult for you to employ someone that will want to be dubious and you won't know. The system would throw the employee up... (PNP1)

...The face of the values are all the HODs... because it is not about the director, the set of people that do make it happen are the heads of the department. They are more or less like the role models for everybody who work in their department. So, they are the value drivers or shall I say moral drivers... (PNP9)

As such, this organisation ingrains certain moral values into its employees especially those that are passed down from the leaders through visible modelling and direct association. From a virtue ethics standpoint, this approach echoes the ideal role leaders ought to play in the community. But in a compromised context, where leaders could demonstrate a dark side by indoctrinating their employees into certain unethical practices, the concern for the moral development of employees becomes apparent (Kohlberg 1986). As expected, the moral values espoused in the leaders creates a moral system that all employees respect and trust because they esteem those who serve as the face of those values (the managers) and therefore have a collectively shared responsibility of watching over the system to ensure there is compliance to known moral standards. This environment of moral awareness and accountability makes it easy for misconducts or violations to be detected.

In making further sense of this context from a theoretical perspective, this paper notes that the communitarian nature of the typical African society comes across in the descriptions of the employees interviewed for this study and from personal observations. Leaders and employees consider themselves as part of the 'PNP family' and have coined terms such as 'PNPian' as though conferring citizenship on themselves. However, it must be noted that this notion 
of communitarianism and family within the firm did not receive positive reviews from all employees. A few employees who had worked in stricter formalised corporate settings complained in informal conversations with the author about the way the familial context bred an atmosphere of informality and familiarity which actually impeded candour in many instances. Therefore, in some instances, communicating facts is hindered by the fear of 'people not wanting to offend others'. In the context of virtue ethics theory and Afro-communitarianism, this echoes some of the concerns Keeley (1988) raised about people claiming to have a rosy view of their communities whereas in reality, there are hidden grievances but more importantly is that this could create a perfect breeding ground for a scandal in the future where people privy to information about a misconduct may be discouraged from whistleblowing to avoid 'creating problems in the firm'.

These issues becomes important for instance in the conceptualisation of happiness within the firm's context—which should be as Bujo (1998) suggested an individual's selfrealisation as enabled by the community which will in turn result into a sense of purpose and fulfilment. Therefore, in summing up one major Afro-communitarian conception of virtue, then, a person exhibits human excellence or virtue just in so far as s/he has character traits that express a prizing of communal or friendly relationships as evident in the context of this case study. Yet, the tension of prizing communal and friendly relationships over individual happiness in the case of misconduct remains a challenge for the African ethics of communitarianism. With this understanding, this paper explores the African primary virtues espoused by the leaders in the case study.

\section{Leadership Virtues in Pharma Nigeria PIc}

Drawing from the interview data, research notes from informal conversations and secondary data sources, this study found that the MD/CEO and his leadership team exhibited four African primary virtues: Truthfulness, Courage, Humility, and Humanity.

\section{Truthfulness}

This virtue also manifests as integrity. Contextually, leaders practice truthfulness in communicating honestly to others (e.g., no deception or falsehoods; Solomon 2003, 2009), honouring promises (Palanski and Yammarino 2007), and taking personal responsibility (Taylor-Bianco and Schermerhorn 2006). In the context of this firm, there seems to be a strong sense of integrity manifested in dealing with external customers. For instance, as an incentive to get their sales figures up, companies typically supply products to their employees at a base rate and employees are allowed to 'mark-up' the prices and sell at a profit which is taken home as a bonus in addition to their monthly salary. In exercising the right to mark-up, a lot of unethical practices can manifest even though many companies, especially the reputable ones regulate the range of mark-ups employees are allowed to employ. In spite of this, employees could be tempted by a desire to make more gain than normal, thereby exceeding the recommended range to pocket more bonus. Often times, the excessive mark-ups may be unknown to their supervisors and leaders who perhaps ought to be concerned with staying ahead of their sales targets. However, this was not the case in the context of this firm. As one of the middle-level managers posited, PNP leaders could reach out to customers on the field to check the prices at which they are being supplied the company's products. In cases where employees have charged more than usual, they are asked to refund such clients and to make formal apologies as the quote below shows:

.... case just happened to weeks ago, somebody called me from Port Harcourt and was asking me the price of a product... and from the discussion, I realised the representative was marking up too much. I investigated and there and then I called the representative and discussed with them, they went back to apologise and did the right thing. (PNP6)

This same virtue manifests in dealings with the firm's suppliers as another employee noted:

PNP believes in the trust relationship between staff between suppliers. PNP would not be caught doing something to you at your back what they won't do in front of you when it comes to suppliers... (PNP2)

This demonstration of truthfulness to customers and suppliers alike in situations that could tempt leaders and employees to behave unethically was further collaborated by findings from secondary data online where certain individuals who claim to be distributors submitted statements that supported the integrity with which the firm deals with its customers. Most of these distributors often referred to the excellence with which the firm operated.

More importantly is that in getting the employees to do the right thing, leaders typically acknowledge the pressures their employees face in the market and demonstrate understanding by communicating directly with subordinates to help their meaning making of the issues as the quote below further suggests:

A lot of them face serious battles but I am able to get them to know that their decisions are important. What you are actually doing today won't just affect you, it affects the company in the long run because where there is no consistency your customers may not believe in whatever you have to offer. (PNP7) 
However, in my informal interactions with other members of staff, an older member of staff raised concerns about how internal matters are dealt with despite the good name the firm has outside of its walls. Further investigations revealed that an internal fraud incident some years back had resulted in the firing of over ten members of staff who colluded with a senior official in defrauding the company. Whilst the firm was commended for taking drastic steps in making an example of the culprits, concerns about the exoneration of the most senior member of staff implicated in the incident left a lot members of staff distraught. The display of bias by the $\mathrm{MD} / \mathrm{CEO}$ by not firing the senior official was ascribed to the 'special relationship' s/he enjoyed with the MD/CEO.

Therefore, the bias in handling this situation amplifies the challenge of how employees who are not in privileged position can be treated as 'scapegoats' through a leader's pronouncements. This issue highlights one of the major flaws of communitarianism in which privileged members of family or community might get away with wrong-doings when in the spirit of common good, the decision to publicly punish such a person would have left a stronger impression of the virtue of truthfulness on employees.

\section{Courage}

In corrupt contexts, unethical actions and practices can be easily justified on the premise that 'it is how things are done'. However, deviating from the custom requires courage. Aristotle defined courage as a character trait that enables leaders to do what is believed to be right without fear (Irwing 1999). This virtue is considered essential because it helps overcome fear and facilitates the practice of one's beliefs regardless of the consequences. The deficiency of this virtue is cowardice. Contextually, leaders exemplify courage "when they take actions that may not be popular and/or may put them at personal risk" (Wang and Hackett 2016, p. 325).

Within the context of this case study, leaders seemed to demonstrate courage in two ways. First, in encouraging employees to own up to wrong practices and rectifying the same. Secondly, in refusing to offer bribes despite the possibility of missing big deals. In both instances, courage is demonstrated in relation to external clients and in dealing with some of the grand challenges presented in the context of the business.

Owning Up To Wrongdoings As highlighted in the previous primary virtue, the nature of market operations in the pharmaceutical industry sits largely on a firm's sales force. In carrying out this duty, there are moral pressures thrust upon employees, which could result in unethical practices such as adding more than required mark-ups to product prices. In instances where employees of PNP have been caught doing this, the leaders have personally owned up to the clients and got their employees to rectify the wrongdoing by apologising and refunding excess figures. This is a demonstration of courage in a context that could easily encourage neglecting such issues in as much as the organisation is making its money. To curtail this and ensure transparency, the organisation publishes the base price of all its products and empowers customers to challenge any salesperson marketing above or below the set prices.

The first thing we did was to change the price to make it a uniform price for everybody and also go round the distributors, send customers a note that is the price if anybody selling lower or higher, it is not from us...

So that when we go out we monitor that as well.... (PNP2)

A quick look at general industry practices suggests such acts of transparency are rare and can be considered as an act of courage as the right things are being done despite the profits or business that may be lost in the process. But given the incident also cited in the previous section, leaders of PNP did not acknowledge or own up to their wrongdoings on the matter. This further highlights that fact that within the context of communitarianism, there is a tendency to conceal any matter that may bring the firm to disrepute especially if the persons involved are meant to be one of the 'faces' of the family. Nonetheless, in dealing with external contextual issues and external customers, the firm has demonstrated widely acknowledged and verifiable courage in righting their wrongs.

Refusal to Bribe Bribery is a common practice in the context. It is endemic yet considered the grease in the wheel of business. Especially in industries where competition is quite stiff, offering bribes is seen as crucial to securing big deals. Given the endemic nature of this practice, therefore, it will require courage to refuse to pay out bribes whilst expecting to get good business from big clients. However, the leadership in this case study demonstrate courage daily by refusing to pay out bribes whilst managing to close out big deals. An employee described one of the forms of bribery pressures faced on their job as follows:

Customers demand a lot but you have to be able to handle it. Initially, some representatives were as if they want to fall into that trap but we (leaders) would let them know that it is a bait, it is not good for your business ethically. If a doctor prescribes based on an amount you are giving, what happens when the doctor gets a higher offer elsewhere? They dump you and you lose out (PNP6)

Instead of paying bribes, leaders have taught their employees to distract potential bribe seekers by demonstrating the value the company's product will add to their business, and also 
by giving gifts that add professional value to the customers. An example of this is paying for their attendance at a major conference or supporting such customer's charity initiatives with expert contributions and at times free products. The quotes below further illustrate these:

...If the doctor sees the need to prescribe your products over another competing product, they will not ask for money. Even if they ask for money... you know you're able to handle his objections truly directing him to the benefits of the product. (PNP5)

We don't give them cash but if they're going on a conference or a course, instead of giving them cash, we can pay for their accommodation. We don't joke with things that have to do with medical conferences, seminars, etc.. (PNP4)

In principle, this approach simply leverages the prevalent gift-giving culture in avoiding the trap of bribery. However, the subsequent positive favours the gifts give the firm with beneficiaries of their largesse cannot be discounted.

Even though the manifestation of courage by leaders of the firm seemed evident in relating with its client and customers, another internal incident mentioned by a staff during our informal chats and also verifiable via online secondary sources highlighted a show of cowardice or lack of assertiveness. In this instance, the MD/CEO's relative occupying one of the managerial positions was in charge of a failing product. Whilst it seemed clear to the members of staff that the failure of the otherwise good product was due to his lack of expertise and poor decision-making on the part of the MD/CEO's relative, the product was never assigned to a competent hand and is now out of production. In the words of the staff member:

$\mathrm{X}$ believes because his father owns the company, he can do whatever he likes. He doesn't know the job and will not engage professionals to help out in pushing the products in the market... What he does is to employ sales girls himself and send them into the market. Those ones always come back without selling a single bottle of the product (PNP 19)

Perhaps had the sentiments in the comments of this staff member been addressed, the product may not have failed completely but the handling of this matter as in the previous incident mentioned earlier strike a common pattern of certain privileged members of the firm 'getting away' with certain acts which staff members believed may have resulted in other members of the community losing their jobs.

\section{Humility}

The cultural context in most African countries allows for a high power-distance. The effect of this on the relationship between leaders and followers, for instance, is that employees are unable to relate directly to their leaders for the fear of being termed as 'disrespectful' or 'rude'. For power-distance to be significantly reduced, leaders have to demonstrate the virtue of humility. With this virtue, leaders bring themselves to the level of their employees without necessarily losing their power or prestige. It makes them accessible to their followers who are able to relate with them on a personal level. This display of humility typified employees' descriptions of the MD, for example in the quote below:

...When I just came in, I had not met the MD, and that day I was working late with my boss. The MD came in and began to have a lengthy chat with me and we were all laughing... when he left my boss said to me that is the MD, I was like WOW... he said you will see that in this organisation people have stayed for 9 , 10, 15 years, something would have made them stay outside of salary...My bosses, they have made my life easy. I don't see work as work... (PNP8)

In another narrative, some employees reported that the humility shown by the leaders is also demonstrated by the non-segregated seating arrangements and freedom of interaction during lunch breaks served in the company restaurant. Employees construe this as atypical given the macro cultural context, however they also claim it has formed a context of freedom where they can speak directly to their bosses without fear.

If I have a brilliant idea, I present it... my supervisor analyses its pros and cons if it is good yes it is good, take it to the director, why don't we adopt it XYZ came up with this idea and I have looked at it, it works... (PNP2)

...One thing I will credit this company for is that the top management has no restrictions on anybody, you can walk up to them and express your feelings and it'll be noted. If it is one that needs to be implemented you will be recognised and commended for it. So, it is one of the reasons why you can see someone like me here... (PNP4)

In the context of this firm, humility as espoused by the leaders was claimed to empower innovativeness in employees as many indicated in their accounts and even suggested that it is known in the firm that employees get recognised and rewarded for sharing thoughts and ideas that improve the overall efficiency of a department or the entire firm. 


\section{Humanity}

Humanity is a character trait underlying leaders' love, care, and respect for others (Wang and Hackett 2016). In practice, humanity could manifest in different forms including encouraging employees to share their thoughts without fear of retribution. However, a significant demonstration of this virtue could be in showing genuine care and help for the disadvantaged or less privileged. In the context of this case study, the highest demonstration of this virtue was shared by a current employee who was rescued from being homeless by the MD of PNP, given his first job as a security guard and has risen to become a human resource officer in the company.

They have given me the opportunity. I was a school dropout when I joined them and I have been given the platform to grow with the company, they learn to identify talents. I am now studying entrepreneurship and business management at the National Open University and I will be finishing soon... (PNP4)

More importantly is that the CEO had since become a role model and mentor to the young man who claims he owes his life to the MD. This virtue of humanity has been further demonstrated in the firm by the more recent campaign of the firm against fake drugs, which has been a major bane of the Nigerian context and is claimed to be responsible for a significant number of deaths annually. In the practice of Afro-communitarianism, these kinds of actions are reasonably expected. In fact, it is such beneficence that African moral philosophers agree upon as the singular most defining trait of an African community. Although a critical thought in this type of magnanimity is that in instances where leaders have sinister motives, they could coerce people they have helped into perpetrating certain unethical practices. Therefore, humanity when practiced without any strings attached is the ideal virtue for afro-communitarianism.

In summary, the functioning of the four African primary virtues espoused in this study's model of virtuous leadership were sustained by key underlying processes and conditions as follows:

1. The overall end of this virtuous leadership model is the flourishing of the immediate and wider community around the leader.

2. The leaders in this context did not use force or coercion in exerting influence. Hence, this model of virtuous leadership is not based on position, power, and bureaucratic structure, rather it is influence based on visible modelling of virtues held as central to the person of the leader.

3. This model of virtuous leadership enabled a gradual formation of character based on constant exposure to leaders' virtues over time. Leaders enabled members of the community to grow by nurturing or guiding them to doing things right as voluntary actions.

4. Moral rule is not the motivation in this model of virtuous leadership. The tendency to act consistently in an admirable manner based on character is the key motivation of this model and this is beyond charisma.

5. Leaders within this model of virtuous leadership are not flawless superheroes. They have visible weaknesses members of the community may overlook because of the visibility of key virtuous characters such as integrity, honesty and trustworthiness.

\section{Conclusion and Implications}

This study has presented a model of virtuous leadership within an African context of communitarianism. In doing this, it explored the features of the macro, industry and firm context within which the understudied leaders practice their model of virtuous leadership whilst also exploring the impact this model of virtuous leadership had on the immediate community of employees. Given the perceived positive impact of the leaders in the case study on their employees, it submits four African primary virtues of truthfulness, courage, humility and humanity as essential for thriving in a compromised wider communitarian context. However in the practice and functioning of this leadership model, an interesting pattern was observed. It seemed evident that in dealing with external issues and matters concerning external members or the wider society, the leaders' virtues were effective and evidence from the wider stakeholder group seemed to confirm this. However, in handling domestic or internal issues, this model of virtuous leadership had its shortcomings particularly with hierarchical privileges seemingly trumping the 'common good'. For instance, privileged members of the upper echelon got away with certain acts other members of the same community were more likely to have been severely punished for as evidenced in two major incidents. Moreover, these actions were sanctioned by the MD/CEO who is considered to be a moral exemplar. This manifestation seems to mirror the functioning of traditional African families, in which members of families protect the dignity of their family names when dealing with external parties, but within the families, there will always be grievances and heads of families run a patriarchal system with almost absolute power in presiding over matters.

This functioning highlights a few possibilities: First, the strong possibility of nepotism within communitarian systems especially towards people closer to the overall head. Second, the tendency for the wider positive image of the firm externally to create a false façade that impedes internal moral contemplation and dialogue which is necessary in the 
virtue ethics tradition for nurturing virtue. This perhaps may also imply that the culture of 'openness' is very superficial on internal matters but effective on external issues. Third, that the MD/CEO could become invincible and that communitarianism with all its good intentions to foster a strong sense of community could fail in fostering a strong enough social accountability system around the leaders at the top to check their moral choices. If in the event of a personal moral failure, as we are all humans, communitarian systems may offer little or no buffer in correcting wrongdoing and restoring the essence of the community's existence. The latter point is the narrative of the wider African society today where leaders are not accountable to even the constitution. Nonetheless, whilst the effectiveness of the model of virtuous leadership presented in this case can be commended for its ability to creatively bypass some of the grave moral issues posed by the wider societal context, it is also clear that for this model of virtuous leadership to retain its chances of improvement and survival in the long run, measures have to be put in place to curtail excesses that threaten the notion of 'common good' within its existence.

This study concludes that within the African context, communities are central but also community leaders play significant roles in shaping the morality of a polity. The practice of certain communal virtues may be encouraged in followers through visible modelling of these virtues by the leaders especially in the habits choices and lifestyles of leaders. However in a compromised context, exercising moral integrity in any form would require a decision to be bold enough to do things differently. In the case study presented, the leadership model espoused four African primary virtues in its operations: Truthfulness, Courage, Humility and Humanity. These four African primary virtues have also been documented by African ethicists as central to the functioning of African societies towards the end of facilitating the flourishing of their immediate and wider communities, as the way to shape individuals and communities alike.

The findings and conclusions above suggest that there are models of leadership that can build thriving organisations within Africa, whilst also positively contributing to the development and enhancement of the moral capacities of employees and the wider society. Moreover, that virtuous leadership models rooted in true African virtue ethics does have significant contributions to make in enhancing our understanding of leadership models that work for Africa. It must however be noted that this study is not without its limitations. The sample size is quite small especially in a qualitative study aiming to present a model further studies can test. Also this study is focused on one industry sector, the pharmaceutical industry. More studies could, therefore, be encouraged towards studying other contexts and industries in order to find a 'unified model' of virtuous leadership that can advance Africa. In addition, this study implies that there could be contextual community features that influence the nature and practice of virtuous leadership in Africa especially at the leadership level. The understanding of the manifestations of these in other African contexts can help towards advancing philosophies and theories that could be adopted in the African management literature. Furthermore, in the training of leaders in our business schools, building curricula to encourage the cultivation of African primary virtues that could shape present and future business leaders becomes pertinent. In the election of leaders, for various positions in organisations and the wider society, our findings imply that there should be certain levels of character orientation potential leaders must exhibit and further studies could help identify other primary virtues that leaders and their followers should prioritise in testing the credibility of the latter for such offices.

Funding This study has not been funded by any research grant.

\section{Compliance with Ethical Standards}

Ethical Approval All procedures performed in studies involving human participants were in accordance with the ethical standards of the institutional and/or national research committee and with the 1964 Helsinki Declaration and its later amendments or comparable ethical standards.

Informed Consent Informed consent was obtained from all individual participants included in the study.

Open Access This article is distributed under the terms of the Creative Commons Attribution 4.0 International License (http://creativeco mmons.org/licenses/by/4.0/), which permits unrestricted use, distribution, and reproduction in any medium, provided you give appropriate credit to the original author(s) and the source, provide a link to the Creative Commons license, and indicate if changes were made.

\section{References}

Agandona. (2009). The Common good of the company and the theory of organisations. Retrieved March 05, 2019, from https://core. ac.uk/download/pdf/6626401.pdf.

Baxter, P., \& Jack, S. (2008). Qualitative case study methodology: Study design and implementation for novice researchers. The Qualitative Report, 13(4), 544-559.

Beadle, R., \& Knight, K. (2012). Virtue and meaningful work. Business Ethics Quarterly, 22(2), 433-450.

Beadle, R., \& Moore, G. (2006). MacIntyre on virtue and organization. Organization Studies, 27(3), 323-340.

Beadle, R., \& Moore, G. (2011). MacIntyre, neo-Aristotelianism and organization theory. In R. Chia \& H. Tsoukas (Eds.), Philosophy and organization theory (pp. 85-121). Bingley: Emerald Group Publishing Limited.

Braun, V., \& Clarke, V. (2006). Using thematic analysis in psychology. Qualitative Research in Psychology, 3(2), 77-101.

Braun, V., Clarke, V., \& Terry, G. (2014). Thematic analysis. Qualitative Research in Clinical and Health Psychology, 24, 95-114. 
Bujo, B. (1998). The ethical dimension of community. Nairobi City: Paulines Publications Africa.

Coe, S., \& Beadle, R. (2008). Could we know a practice-embodying institution if we saw one? Philosophy of Management, 7(1), 9-19.

Crossan, M., Mazutis, D., \& Seijts, G. (2013). In search of virtue: The role of virtues, values and character strengths in ethical decisionmaking. Journal of Business Ethics, 113(4), 567-581.

Erhun, W. O., Babalola, O. O., \& Erhun, M. O. (2001). Drug regulation and control in Nigeria: The challenge of counterfeit drugs. Journal of Health and Population in Developing Countries, 4(2), 23-34.

Everett, J., Neu, D., \& Rahaman, A. S. (2006). The global fight against corruption: A Foucaultian, virtues-ethics framing. Journal of Business Ethics, 65(1), 1-12.

Garuba, H. A., Kohler, J. C., \& Huisman, A. M. (2009). Transparency in Nigeria's public pharmaceutical sector: Perceptions from policy makers. Globalization and health, 5(1), 14.

Gyekye, K. (1992). Person and Community in African Thought. In K. Wiredu \& K. Gyekye (Eds.), Person and community: Ghanaian philosophical studies, I (pp. 101-122). Washington, DC: Council for Research in Values and Philosophy.

Hackett, R. D., \& Wang, G. (2012). Virtues and leadership: An integrating conceptual framework founded in Aristotelian and Confucian perspectives on virtues. Management Decision, 50(5), 868-899.

Hursthouse, R. (2007). Environmental virtue ethics. In R. L. Walker \& P. J. Ivanhoe (Eds.), Working virtue: Virtue ethics and contemporary moral problems (pp. 155-171). Oxford: Clarendon Press.

IMS Health. (2012). Pharmerging markets. Retrieved January 12, 2016, from https://www.imshealth.com/files/web/Global/Services/Servi ces\%20TL/IMS_Pharmerging_WP.pdf.

Irwing. 1999

Juurikkala, O. (2012). Likeness to the divinity? Virtues and charismatic leadership. EJBO., 17, 4-15.

Keeley, M. (1988). A social contract theory of organizations. Notre Dame, IN: Notre Dame Press.

Kohlberg, L. (1986). A current statement on some theoretical issues. In S. Modgil \& C. Modgil (Eds.), Lawrence Kohlberg: Consensus and controversy (pp. 485-546). London: The Falmer Press.

Limbs, E. C., \& Fort, T. L. (2000). Nigerian business practices and their interface with virtue ethics. Journal of Business Ethics, 26(2), $169-179$.

Malunga, C. (2006). Learning leadership development from African cultures: A personal perspective. INTRAC PraxisNote, 25, 1-13.

Masango, M. (2003). Leadership in the African context. The Ecumenical Review, 55(4), 313-321.

Masolo, D. (2010). Self and community in a changing world. Bloomington: Indiana University Press.

Mbigi, L. (2007). Spirit of African leadership: A comparative African perspective. In K. A. April \& M. L. Shockley (Eds.), Diversity (pp. 294-303). London: Palgrave Macmillan.

Melé, D. (2005). Ethical education in accounting: Integrating rules, values and virtues. Journal of Business Ethics, 57(1), 97-109.

Metz, T. (2012). An African theory of moral status: A relational alternative to individualism and holism. Ethical Theory and Moral Practice, 15(3), 387-402.

Metz, T. (2013). The virtues of African ethics. In S. Van Hooft (Ed.), The handbook of virtue ethics (pp. 276-284). Durham: Acumen Publishing.

Metz, T., \& Gaie, J. B. (2010). The African ethic of Ubuntu/Botho: Implications for research on morality. Journal of moral education, 39(3), 273-290.

Mnyaka, M., \& Motlhabi, M. (2005). The African concept of Ubuntu/ botho and its socio-moral significance. Black Theology, 3(2), 215-237.

Moore, G. (2008). Re-imagining the morality of management: A modern virtue ethics approach. Business Ethics Quarterly, 18(4), 483-511.
Murphy, P. E. (1999). Character and virtue ethics in international marketing: An agenda for managers, researchers and educators. Journal of Business Ethics, 18(1), 107-124.

Muxe Nkondo, G. (2007). Ubuntu as public policy in South Africa: A conceptual framework. International Journal of African Renaissance Studies, 2(1), 88-100.

National Agency for Food and Drugs Administration and Control (NAFDAC). (2015). Drug Regulation. Retrieved December 06, 2016, from http://www.nafdac.gov.ng/index.php/regulation/drug-regul ations.

Neubert, M. J. (2011). Introduction: The value of virtue to management and organizational theory and practice. Canadian Journal of Administrative Sciences/Revue Canadienne des Sciences de l'Administration, 28(3), 227-230.

Ngambi, H. C. (2011). The relationship between leadership and employee morale in higher education. African Journal of Business Management, 5(3), 762-776.

Nkomo, S. M. (2011). A postcolonial and anti-colonial reading of 'African'leadership and management in organization studies: Tensions, contradictions and possibilities. Organization, 18(3), 365-386.

Palanski, M. E., \& Yammarino, F. J. (2007). Integrity and leadership: Clearing the conceptual confusion. European Management Journal, 25(3), 171-184.

Palanski, M. E., \& Yammarino, F. J. (2009). Integrity and leadership: A multi-level conceptual framework. The Leadership Quarterly, 20(3), 405-420.

Papouli, E. (2018). Aristotle's virtue ethics as a conceptual framework for the study and practice of social work in modern times. European Journal of Social Work, 22, 921-934.

Paris, P. J. (1995). The spirituality of African peoples: The search for a common moral discourse. Minneapolis: Fortress Press.

Shutte, A. (2001). Ubuntu: An ethic for a new South Africa. Pietermaritzburg: Cluster Publications.

Sison, A. J. G., \& Fontrodona, J. (2012). The common good of the firm in the Aristotelian-Thomistic tradition. Business Ethics Quarterly, 22(2), 211-246.

Solomon, R. C. (2003). Victims of circumstances? A defense of virtue ethics in business. Business Ethics Quarterly, 13(1), 43-62.

Solomon, R. C. (2009). Morality and the good life: An introduction to ethics through classical sources. New York: McGraw-Hill.

Spangenberg, H. H., \& Theron, C. C. (2002). Development of a uniquely South African leadership questionnaire. South African Journal of Psychology, 32(2), 9-25.

Spreitzer, G. M., \& Sonenshein, S. (2003). Positive deviance and extraordinary organizing. Positive organizational scholarship, 207, 224.

Strauss, A., \& Corbin, J. (1994). Grounded theory methodology. Handbook of qualitative research, 17, 273-285.

Taylor-Bianco, A., \& Schermerhorn, J., Jr. (2006). Self-regulation, strategic leadership and paradox in organizational change. Journal of Organizational Change Management, 19(4), 457-470.

Thun, B., \& Kevin Kelloway, E. (2011). Virtuous leaders: Assessing character strengths in the workplace. Canadian Journal of Administrative Sciences/Revue Canadienne des Sciences de l'Administration, 28(3), 270-283.

Transparency International. (2018). Global Corruption Perception Index. Retrieved January 01, 2019, from https://www.transparency.org/files /content/pages/2018_CPI_Executive_Summary.pdf.

United Nations Industrial Development Organisation (UNIDO). (2013). Pharmaceutical Sector profile on Nigeria. pp. 1-87. Retrieved from https://www.unido.org/fileadmin/user_media/Services/PSD/BEP/ Nigeria_Pharma\%20Sector\%20Profile_032011_Ebook.pdf.

Wang, G., \& Hackett, R. D. (2016). Conceptualization and measurement of virtuous leadership: Doing well by doing good. Journal of Business Ethics, 137(2), 321-345. 
Williams, A. (2003). On the subject of kings and queens:" Traditional" African leadership and the diasporal imagination. African Studies Quarterly, 7(1), 59-67.

World Bank. (2014). Doing Business Annual Report 2014. Retrieved April 12, 2015, from http://www.doingbusiness.org/ /media/ GIAWB/Doing\%20Business/Documents/Annual-Reports/English/ DB14-Full-Report.pdf.

World Bank. (2019). Doing business 2019. Retrieved February 19, 2019, from http://www.doingbusiness.org/content/dam/doingBusiness/ country/n/nigeria/NGA.pdf.
Publisher's Note Springer Nature remains neutral with regard to jurisdictional claims in published maps and institutional affiliations. 